\title{
Scale-selective polarimetry of the birefringence distribution of myocardium tissue
}

Yu. O. Ushenko, O. Vanchuliak, G. B. Bodnar, V. O. Ushenko, N. Pavlyukovich, et al. 


\title{
Scale-selective polarimetry of the birefringence distribution of myocardium tissue
}

\author{
Yu.O. Ushenko ${ }^{a}$ O. Vanchuliak ${ }^{b}$, G.B. Bodnar ${ }^{b}$, V.O. Ushenko ${ }^{a}$, N. Pavlyukovich ${ }^{b}$, \\ O.V. Pavlyukovich ${ }^{\mathrm{b}}$, O. Antonyuk \\ ${ }^{a}$ Chernivtsi National University, 2 Kotsyubinsky Str., Chernivtsi, 58012, Ukraine \\ ${ }^{\mathrm{b}}$ Bukovinian State Medical University, Chernivtsi, 58000, Ukraine
}

\begin{abstract}
In the approximation of weak phase fluctuations, a polarization-correlation method for diagnosing the optical anisotropy of small-scale optically anisotropic fibrillar structures of myocardial tissues is proposed.The algorithms of analytical description and experimental determination of the coordinate distributions of the value of the modulus and phase of "two-point" Stokes vector parameters are defined. Within the statistic, correlation and fractal analysis the possibility of differential diagnostics of slight changes in optical anisotropy of myocardial tissues of different pathological states. The comparative analysis of objective statistical, correlation and fractal analysis of distributions of "single-point" polarization azimuth and ellipticity and "two-point" Stokes vector parameters of polarization-inhomogeneous images of the studied histological sections demonstrated excellent accuracy $(A c \succ 90 \%)$ of differential diagnostics of changes in the optical anisotropy myocardium tissues.
\end{abstract}

Keywords: optics, photonics, light, lasers, templates, journals.

\section{INTRODUCTION}

In the series of research works the possibility of polarimetry diagnostic ${ }^{1-19}$ of optically anisotropic layers of biological tissues ${ }^{20-22}$ and fluids ${ }^{23-29}$ is demonstrated.

This research aims to study fundamental potentiality of the new Stokes-polarimetry approach to polarization-correlation mapping of microscopic images of ischemic heart disease and acute coronary insufficiency died patients myocardial tissue.

\section{THEORY OF THE METHOD}

T.Setola, Ya.Tervo and A.T.Friberg ${ }^{30,31}$ proposed to describe the correlation structure of the stationary distributions of the fields of complex amplitudes of laser light converted by optically anisotropic biological layers, one can use the following mutual spectral density matrix

$$
W_{i, j}\left(r_{1}, r_{2}\right)=E_{i}^{*}\left(r_{1}\right) \cdot E_{j}\left(r_{2}\right), i, j=x, y
$$

Here $r_{1}$ and $r_{2}$ - the coordinates of the neighboring points in the field of laser radiation.

In the approximation of weak phase fluctuations using relations (1) we obtained the following expressions for to calculate the polarization parameters that characterize the birefringence of small-scale structures of the myocardium

$$
\left\{\begin{array}{l}
\left|S_{1}\right|=\left[1+\operatorname{tg} \rho_{1} \operatorname{tg} \rho_{2}\right] \\
\operatorname{Arg} S_{1}=\operatorname{arctg}\left[\frac{\left(\delta_{2}-\delta_{1}\right)}{1+\operatorname{ctg} \rho_{1} \operatorname{ctg} \rho_{2}}\right]
\end{array}\right.
$$

Biosensing and Nanomedicine X, edited by Hooman Mohseni, Massoud H. Agahi, Manijeh Razeghi, Proc. of SPIE Vol. 10352, 103520R - (C) 2017 SPIE · CCC code: 0277-786X/17/\$18 · doi: 10.1117/12.2273743 


$$
\begin{gathered}
\left\{\begin{array}{l}
\left|S_{2}\right|=\left[1-\operatorname{tg} \rho_{1} \operatorname{tg} \rho_{2}\right] \\
\operatorname{Arg} S_{2}=\operatorname{arctg}\left[\frac{\left(\delta_{2}-\delta_{1}\right)}{\operatorname{ctg} \rho_{1} \operatorname{ctg} \rho_{2}}\right]
\end{array}\right. \\
\left\{\begin{array}{l}
\left|S_{3}\right|=1-\operatorname{ctg} \rho_{2} \operatorname{tg} \rho_{1} ; \\
\operatorname{Arg} S_{3}=\operatorname{arctg}\left(\frac{\delta_{2}-\delta_{1} \operatorname{ctg} \rho_{2} \operatorname{tg} \rho_{1}}{1+\operatorname{ctg} \rho_{2} \operatorname{tg} \rho_{1}}\right) ;
\end{array}\right. \\
\left\{\begin{array}{l}
\left|S_{4}\right|=1+\operatorname{ctg} \rho_{2} \operatorname{tg} \rho_{1} ; \\
\operatorname{Arg} S_{4}=\operatorname{arctg}\left(\frac{1+\operatorname{ctg} \rho_{2} \operatorname{tg} \rho_{1}}{\delta_{1}+\delta_{2} \operatorname{ctg} \rho_{2} \operatorname{tg} \rho_{1}}\right)
\end{array}\right.
\end{gathered}
$$

It follows from the analysis of the obtained relations (2) - (4) that the SCP modulus $\left|S_{i=1 ; 2 ; 3 ; 4}(\Delta x, \Delta y)\right|$ carries information about the orientation structure $\rho(x, y)$ of polycrystalline networks and structures. The SCP phase $\operatorname{Arg}\left(S_{i=1 ; 2 ; 3 ; 4}(\Delta x, \Delta y)\right)$ carries information about their birefringence $(\delta(x, y))$.

\section{MATERIALS AND METHODS}

Measurement of the coordinate distributions of the values of $\left|S_{i=3}(\Delta x ; \Delta y)\right| ; \operatorname{Arg}\left(S_{i=3}(\Delta x ; \Delta y)\right)$ and $\mid S_{i=4}(\Delta x ; \Delta y) ; \operatorname{Arg}\left(S_{i=4}(\Delta x ; \Delta y)\right)$ was carried out in the experimental arrangement of Stokes-polarimeter ${ }^{9,13,17}$.

\section{BRIEF DESCRIPTION OF THE RESEARCH OBJECTS}

Optically thin (attenuation coefficient $\tau \prec 0.01$ ) samples of histological sections (geometrical thickness $l=25 \mu m \div 30 \mu m \quad 0.0093 \leq \tau \leq 0.0099$ ) of myocardium biological tissues of internals of two statistically significant (37 samples each) groups.

Histological sections of biological tissues of rat's internal were produced by the standard technique in freezing microtome.

\section{EXPERIMENTAL RESULTS AND DISCUSSION}

In the series of Fig. 1 - Fig. 4 is shown the cross-correlation functions of the coordinate distributions of the modulus (Fig.1, Fig.2) and the phases (Fig.3, Fig.4) of the polarization-correlation parameters of the Stokes vector images of the histological sections of the myocardium with IHD (Figure 1, Figure 3) and ACI (Figure 2, Figure 4). 

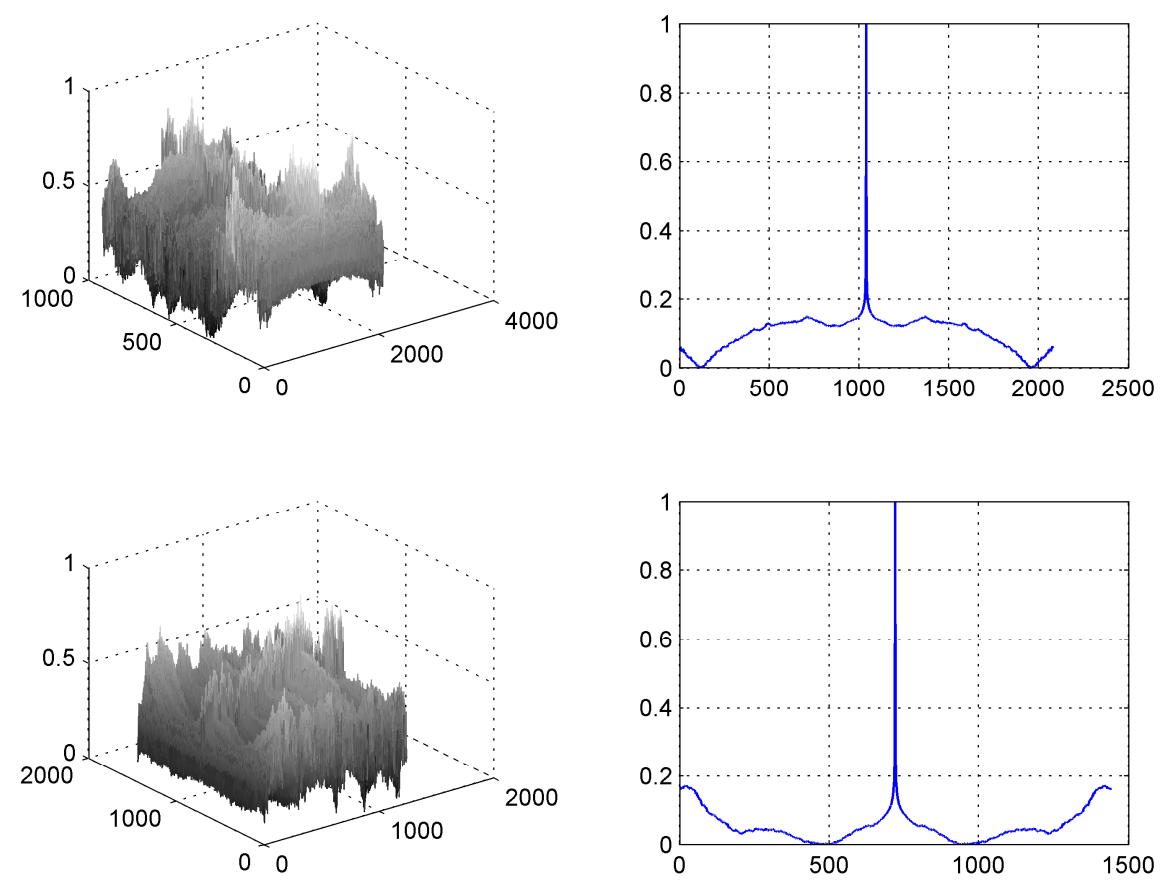

Figure. 1. Cross-correlation functions of polarization parameters modulus of the myocardium with IHD histological section image
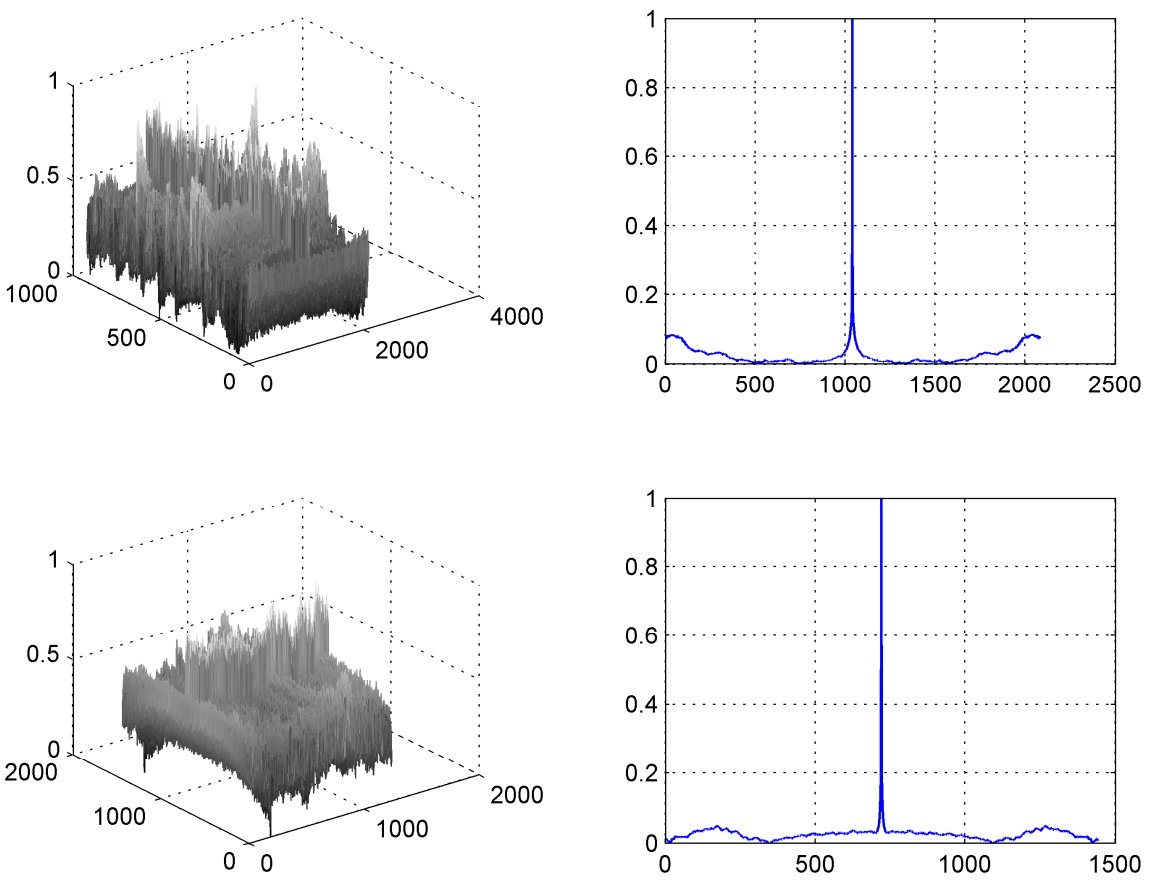

Figure. 2. Cross-correlation functions of polarization parameters modulus of the myocardium with ACI histological section image 

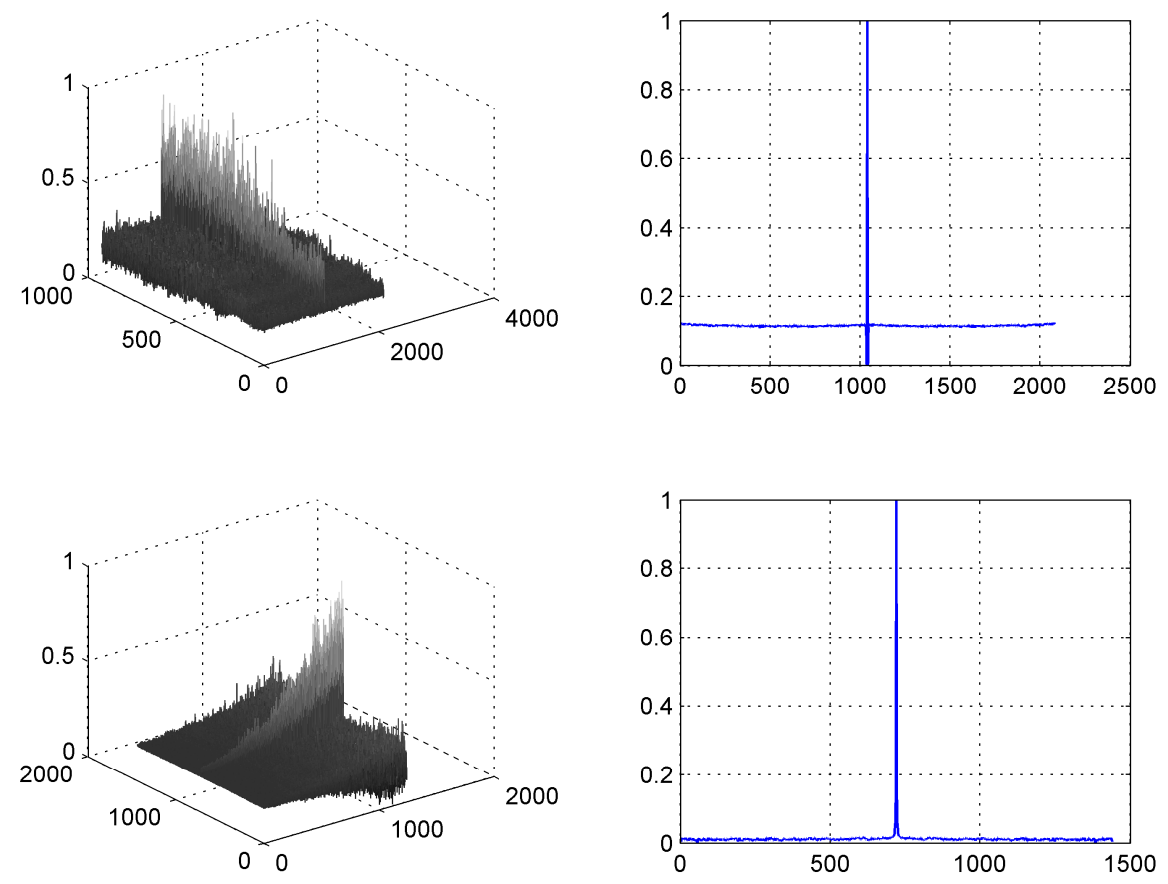

Figure. 3. Cross-correlation functions of polarization parameters phase of the myocardium with IHD histological section image
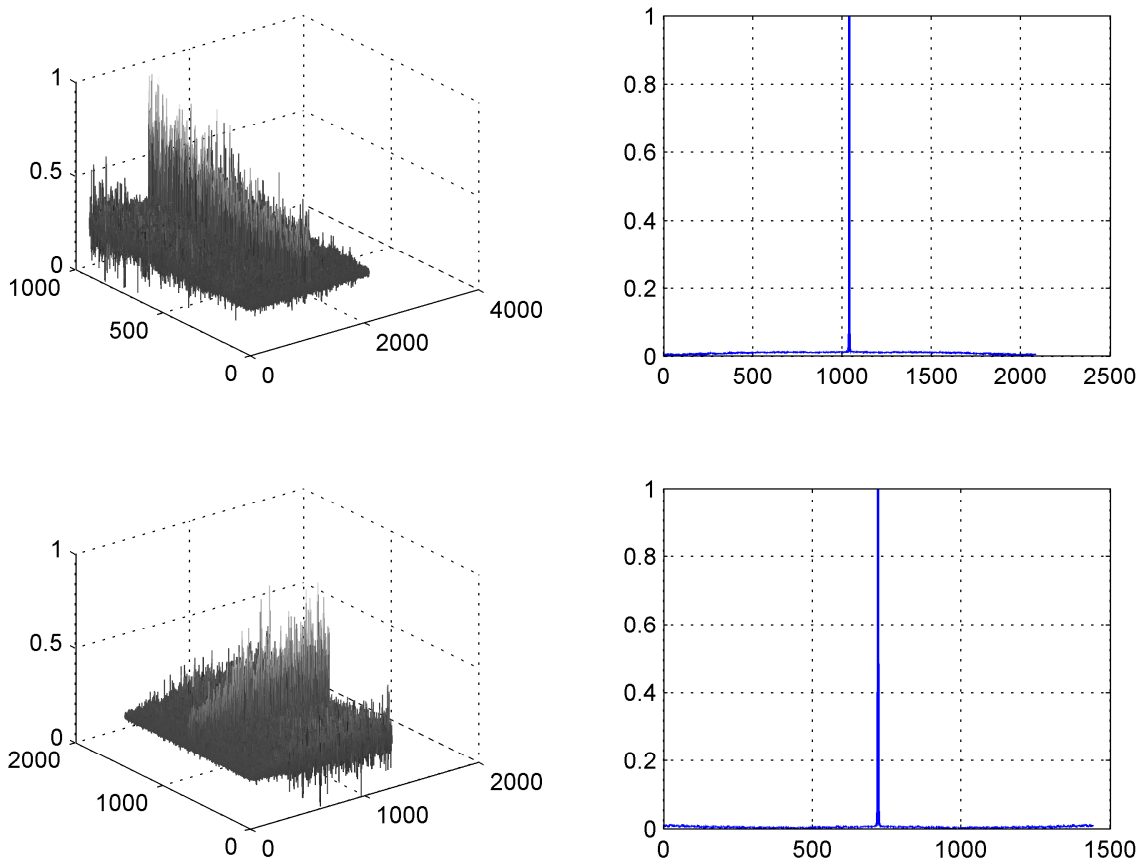

Figure. 4. Cross-correlation functions of polarization parameters phase of the myocardium with ACI histological section image

The potentiality of Stokes-correlometry differentiation of the two groups of myocardium samples is quantitatively illustrated by the data presented in Table 1 and Table 2 . 
Table 1. Correlation parameters of SCP modulus maps of polarization-inhomogeneous images of histological sections of myocardium

\begin{tabular}{|c|c|c|c|c|}
\hline Parameters & \multicolumn{2}{|c|}{$\left|S_{i=3}(\Delta x, \Delta y)\right|$} & \multicolumn{2}{|c|}{$\left|S_{i=4}(\Delta x, \Delta y)\right|$} \\
\hline Condition & $\begin{array}{c}\text { IHD } \\
(n=39)\end{array}$ & $\begin{array}{c}\text { ACI } \\
(n=39)\end{array}$ & $\begin{array}{c}\text { IHD } \\
(n=39)\end{array}$ & $\begin{array}{c}\text { ACI } \\
(n=39)\end{array}$ \\
\hline$Z_{2}^{k}$ & $0,077 \pm 0,0052$ & $0,13 \pm 0,0092$ & $0,065 \pm 0,0053$ & $0,093 \pm 0,0072$ \\
\hline$Z_{4}^{k}$ & $2,34 \pm 0,19$ & $0,92 \pm 0,073$ & $1,68 \pm 0,15$ & $0,89 \pm 0,063$ \\
\hline
\end{tabular}

Table 2. Correlation parameters of SCP phase maps of polarization-inhomogeneous images of histological sections of myocardium

\begin{tabular}{|c|c|c|c|c|}
\hline Parameters & \multicolumn{2}{|c|}{$\operatorname{Arg}\left(S_{i=3}(\Delta x ; \Delta y)\right)$} & \multicolumn{2}{c|}{$\operatorname{Arg}\left(S_{i=4}(\Delta x ; \Delta y)\right)$} \\
\hline Condition & $\begin{array}{c}\text { IHD } \\
(n=39)\end{array}$ & $\begin{array}{c}\text { ACI } \\
(n=39)\end{array}$ & $\begin{array}{c}\text { IHD } \\
(n=39)\end{array}$ & $\begin{array}{c}\text { ACI } \\
(n=39)\end{array}$ \\
\hline$Z_{2}^{k}$ & $0,065 \pm 0,0053$ & $0,12 \pm 0,009$ & $0,045 \pm 0,0035$ & $0,067 \pm 0,0054$ \\
\hline$Z_{4}^{k}$ & $3,24 \pm 0,19$ & $1,38 \pm 0,073$ & $4,41 \pm 0,42$ & $2,43 \pm 0,038$ \\
\hline
\end{tabular}

The data analysis revealed the following differences between the set of objective parameters that characterize the maps of SCP-modulus of polarization-inhomogeneous images of both types myocardium histological sections:

- $\Delta Z_{2}^{k}=1.45-1.52$ times; $\Delta Z_{4}^{k}=1.82-2.43$ times;

These data were obtained for the SCP phase distributions:

- $\Delta Z_{2}^{k}=1.34-1.61$ times; $\Delta Z_{4}^{k}=1.89-2.37$ times;

\section{COMPARATIVE EFFICIENCY OF THE TECHNIQUES OF LASER POLARIMETRY AND STOKES-CORRELOMETRY OF POLARIZATION- INHOMOGENEOUS IMAGES OF HISTOLOGICAL SECTIONS}

The Stokes-correlometry method of SCP modulus $\left|S_{i=3 ; 4}(\Delta x ; \Delta y)\right|$ and phase $\operatorname{Arg}\left(S_{i=3 ; 4}(\Delta x ; \Delta y)\right)$ distributions of polarization-inhomogeneous images was compared with the that of polarization mapping of distributions of the values of azimuth and ellipticity of the corresponding microscopic images of histological sections of myocardium (Table 3).

For the possible clinical application of both methods the following was determined for each group of samples ${ }^{32-38}$ traditional for probative medicine operational characteristics - sensitivity $\left(S e=\frac{a}{a+b} 100 \%\right)$, specificity $\left(S p=\frac{c}{c+d} 100 \%\right)$ and balanced accuracy $\left(A c=\frac{S e+S p}{2}\right)$, where $a$ and $b$ are the number of correct and wrong diagnoses within group $2 ; c$ and $d-$ the same within group 1 - Table 5. 
Table 3. Accuracy of the methods of Stokes-correlometry and laser polarimetry of myocardium tissue in the differential diagnostics of pathologies

\begin{tabular}{|c|c|c|c|c|c|c|}
\hline \multirow{2}{*}{ Parameters } & \multicolumn{7}{|c|}{$A c, \%$} & & \multicolumn{5}{c|}{$(x, y)$} \\
\cline { 2 - 7 } & $\left|S_{3}\right|$ & $\left|S_{4}\right|$ & $A r g S_{3}$ & $\operatorname{Arg} S_{4}$ & $\alpha(x, y)$ & $\beta(x, y)$ \\
\hline$Z_{2}^{k}$ & 84 & 81 & 86 & 87 & 69 & 74 \\
\hline$Z_{4}^{k}$ & 92 & 94 & 95 & 96 & 84 & 81 \\
\hline
\end{tabular}

\section{CONCLUSION}

A new method of polarization - correlometry - determination of the coordinate distributions of the modulus and phase of "two-point" Stokes-vector parameters of polarization-inhomogeneous images of histological sections of biological tissues of myocardium is suggested and analytically substantiated.

Within the correlation analysis the objective criteria characterizing the SCP-maps of polarization- inhomogeneous microscopic images of two groups (IHD-ACI) of samples of biological tissues of myocardium with the structured collagen birefringent fibrillar networks are determined.

The comparative analysis of the objective correlation analysis of distributions of polarization "single-point" azimuth and ellipticity and "two-point" Stokes-vector parameters of polarization-inhomogeneous images of histological sections under study demonstrated the excellent accuracy $(A c \succ 90 \%)$ of differential diagnostics of changes in optical anisotropy of myocardium by the polarization - correlometry method.

\section{REFERENCES}

[1] Müller G. et al., Eds., "Medical Optical Tomography: Functional Imaging and Monitoring, Vol. IS11, SPIE Press, Bellingham, Washington (1993).

[2] Yao G., Wang V., "Two-dimensional depth-resolved Mueller matrix characterization of biological tissue by optical coherence tomography" Opt. Lett, V. 24, 537-539 (1999).

[3] Lu S. Chipman R. A., "Interpretation of Mueller matrices based on polar decomposition", J. Opt. Soc. Am. A, Vol. 13, 1106-1113 (1996).

[4] Tuchin V. V., [Light scattering study of tissues], Physics-Uspekhi 40(5), 495-515 (1997).

[5] Tower T. T., Tranquillo R. T., "Alignment Maps of Tissues: I. Microscopic Elliptical Polarimetry" Vol. 81, 2954-2963 (2001).

[6] Angelsky, O. V., Gorsky, M. P., Hanson, S. G., Lukin, V. P., Mokhun, I. I., Polyanskii, P. V., Ryabiy, P. A., "Optical correlation algorithm for reconstructing phase skeleton of complex optical fields for solving the phase problem," Opt. Exp. 22(5), 6186-6193 (2014).

[7] Ushenko, A. G., Burkovets, D. N., Ushenko, Y. A., "Polarization-phase mapping and reconstruction of biological tissue architectonics during diagnosis of pathological lesions," Optics and Spectroscopy, 93(3), 449-456 (2002).

[8] Ushenko, A. G., "Polarization correlometry of angular structure in the microrelief pattern of rough surfaces," Optics and spectroscopy, 92(2), 227-229 (2002).

[9] Angelsky, O. V., Ushenko, A. G., Ushenko, Y. G., Tomka, Y. Y., "Polarization singularities of biological tissues images," Journal of biomedical optics, 11(5), 054030-054030 (2006).

[10] Ushenko, A. G., "Laser diagnostics of biofractals," Quantum electronics, 29(12), 1078 (1999).

[11] Angelsky, O. V., Bekshaev, A. Ya., Maksimyak, P. P., Maksimyak, A. P., Hanson, S. G., Zenkova, C. Yu., "Self-diffraction of continuous laser radiation in a disperse medium with absorbing particles," Optics Express 21(7), 8922-8938, (2013).

[12] Angelsky, O. V., Bekshaev, A. Ya., Maksimyak, P. P., Maksimyak, A. P., Hanson, S. G., Zenkova, C. Yu., "Self-action of continuous laser radiation and Pearcey diffraction in a water suspension with light-absorbing particles," Optics Express 22(3), 2267-2277, (2014). 
[13] Angelsky O.V., Ushenko A.G., Ushenko Yu.A., Pishak V.P., Peresunko A.P., "Statistical, Correlation and Topological Approaches in Diagnostics of the Structure and Physiological State of Birefringent Biological Tissues" in Handbook of Photonics for Biomedical Science, CRC Press, Taylor\&Francis group: Boca Raton, London, New York, 283-322 (2010).

[14] Boas D., Pitris C., and Ramanujam N., Handbook of Biomedical Optics, CRC Press, Boca Raton, London, New York (2011).

[15] Ghosh N.and Vitkin I. A., "Tissue polarimetry: concepts, challenges, applications and outlook,” J. Biomed. Opt. 16, 110801 (2011).

[16] Jacques S. L., "Polarized light imaging of biological tissues" in Handbook of Biomedical Optics, CRC Press, Boca Raton, London, New York, 649-669 (2011).

[17] Ushenko Y.A., Boychuk T.M., Bachynsky V.T., Mincer O.P., "Diagnostics of Structure and Physiological State of Birefringent Biological Tissues: Statistical, Correlation and Topological Approaches" in Handbook of Coherent-Domain Optical Methods, ISBN 978-1-4614-5175-4. Springer Science+Business Media New York, 107-148 (2013).

[18] Angelsky, O.V., Hanson, S.G., Maksimyak, P.P., Maksimyak, A.P., Zenkova, C.Yu., Polyanskii, P.V., Ivanskyi, D.I., "Influence of evanescent wave on birefringent microplates," Opt. Express 25, 2299-2311 (2017).

[19] Angelsky, O. V., Bekshaev, A. Ya., Maksimyak, P. P., Maksimyak, A. P., Hanson, S. G., Kontush, S. M., "Controllable generation and manipulation of micro-bubbles in water with absorptive colloid particles by $\mathrm{CW}$ laser radiation," Opt. Express 25, 5232-5243 (2017).

[20] Ushenko V. A., Gavrylyak M. S., "Azimuthally invariant Mueller-matrix mapping of biological tissue in differential diagnosis of mechanisms protein molecules networks anisotropy" SPIE 8812, Biosensing and Nanomedicine VI, 88120Y (September 11, 2013).

[21] Ushenko V. O. "Two-dimensional Mueller matrix phase tomography of self-similarity birefringence structure of biological tissues“" Proc. SPIE 8487, Novel Optical Systems Design and Optimization XV, 84870W (October 19, 2012).

[22] Angelsky, O. V., Bekshaev, A. Ya., Maksimyak, P. P., Maksimyak, A. P., Hanson, S. G., "Measurement of small light absorption in microparticles by means of optically induced rotation," Optics Express 23(6), 71527163 (2015).

[23] Ushenko Yu. A., Ushenko V. A., Dubolazov A. V., Balanetskaya V. O., and Zabolotna N. I. "Mueller-matrix diagnostics of optical properties of polycrystalline networks of human blood plasma" Optics and Spectroscopy, Volume 112, Issue 6, 884-892 (June 2012).

[24] Ushenko Yu. A., Dubolazov A. V., Balanetskaya V. O., Karachevtsev A. O., Ushenko V. A., "Waveletanalysis of polarization maps of human blood plasma" Optics and Spectroscopy, Volume 113, Issue 3, $332-$ 343 (September 2012).

[25] Ushenko V. O., "Spatial-frequency polarization phasometry of biological polycrystalline networks" Optical Memory and Neural Networks, Volume 22, Issue 1, 56-64 (March 2013).

[26] Ushenko V. A., Dubolazov O. V., Karachevtsev A. O., "Two wavelength Mueller matrix reconstruction of blood plasma films polycrystalline structure in diagnostics of breast cancer" Applied Optics, Vol. 53, Issue 10, B128-B139 (2014).

[27] Angelsky, P. O., Ushenko, A. G., Dubolazov, A. V., Sidor, M. I., Bodnar, G. B., Koval, G., Trifonyuk, L., "The singular approach for processing polarization-inhomogeneous laser images of blood plasma layers," Journal of Optics, 15(4), 044030 (2013).

[28] Dubolazov, A. V., Marchuk, V., Olar, O. I., Bachinskiy, V. T., Vanchuliak, O. Y., Pashkovska, N. V., Kostiuk, S. V., "Multiparameter correlation microscopy of biological fluids polycrystalline networks," In Eleventh International Conference on Correlation Optics, International Society for Optics and Photonics, pp. 90661Y-90661Y (2013).

[29] Ushenko, O., Dubolazov, A., Balanets' ka, V., Karachevtsev, A., Sydor, M., "Wavelet analysis for polarization inhomogeneous laser images of blood plasma," Proc. SPIE 8338 (2011).

[30] Ushenko, V. A., O. V. Dubolazov, A. O. Karachevtsev, "Two wavelength Mueller matrix reconstruction of blood plasma films polycrystalline structure in diagnostics of breast cancer," Applied optics 53(10), B128B139 (2014). 
[31] Tervo J., Setala T., Friberg A., "Two-point Stokes parameters: interpretation and properties," Optics Letters 34(20), 3074-3076 (2009).

[32] Ushenko Yu. A., Gorskii M. P., Dubolazov A. V., Motrich A. V., Ushenko V. A., Sidor M. I., "Spatialfrequency Fourier polarimetry of the complex degree of mutual anisotropy of linear and circular birefringence in the diagnostics of oncological changes in morphological structure of biological tissues" Quantum Electron, Volume 42(8) (2012).

[33] Ushenko, V. A. "Complex degree of mutual coherence of biological liquids" Proc. SPIE 8882, 88820V (June 10, 2013).

[34] Ushenko V. A., Gorsky M. P., "Complex degree of mutual anisotropy of linear birefringence and optical activity of biological tissues in diagnostics of prostate cancer" Optics and Spectroscopy, Volume 115, Issue 2, 290-297 (August 2013).

[35] Ushenko,Yu. A., Bachynsky, V. T., Vanchulyak, O. Ya., Dubolazov, A. V., Garazdyuk, M. S., and Ushenko, $\mathrm{V}$. A., "Jones-matrix mapping of complex degree of mutual anisotropy of birefringent protein networks during the differentiation of myocardium necrotic changes," Appl. Opt. 55, B113-B119 (2016).

[36] Cassidy, "Basic concepts of statistical analysis for surgical research," Journal of Surgical Research 128,199206 (2005).

[37] C. S. Davis, "Statistical methods of the analysis of repeated measurements" 744, New York: Springer-Verlag (2002).

[38] A. Petrie, B. Sabin, [Medical Statistics at a Glance], pp. 157, Blackwell Publishing (2005). 